\title{
Mercado de trabajo fueguino y desigualdad de género. Análisis de los perfiles sociales y ocupacionales de las jefas y jefes de hogar en Tierra del Fuego, Antártida e Islas del Atlántico Sur. 2003-2015
}

Fuegian labor market and gender inequality. Analysis of social and occupational profiles of female heads of household in Tierra del Fuego, Antarctica and South Atlantic Islands. 2003-2015.

Daniela S. Chamorro

Instituto de Cultura, Sociedad y Estado, Universidad Nacional de Tierra del Fuego, Antártida e Islas del Atlántico Sur, Argentina

chamorrodaniela1@gmail.com

Lucila M. Ochoa

Instituto de Cultura, Sociedad y Estado, Universidad Nacional de Tierra del Fuego, Antártida e Islas del Atlántico Sur, Argentina

lucila111ochoa@gmail.com

\section{Resumen:}

La presente investigación consiste en una primera aproximación a la caracterización de los perfiles familiares y laborales de las jefaturas de los hogares de Tierra del Fuego durante el período 2003-2015. Aborda diferenciada y comparativamente los perfiles de jefatura femenina y jefatura masculina según su incidencia en el mercado de trabajo y sus condiciones socio-laborales de forma contrapuesta a sus roles dentro del ámbito privado-familiar. De esta manera, se logra dar cuenta de la desigualdad de género a partir de la división sexual del trabajo y sus implicancias expresas en los distintos perfilamientos.

Palabras Clave: División sexual del trabajo, Trabajo de reproducción, Trabajo doméstico, Jefaturas de hogar, Empleo.

\section{Abstract:}

The present investigation consists of a first approximation to the characterization of the family and labor profiles of the heads of households of Tierra del Fuego during the period 2003-2015. It addresses the profiles of female and male headship differently and comparatively according to their incidence in the labor market and their socio-labor conditions as opposed to their roles within the private-family sphere. In this way, it is possible to account for gender inequality based on the sexual division of labor and its explicit implications in the different profiles.

KEYworDs: Sexual division of labor, Reproduction work, Domestic work, Head of household, Employment.

\section{INTRODUCCIÓN}

Desde fines del siglo XX, las teorías económicas han ido transformando la producción de conocimiento científico respecto a las relaciones de producción capitalista e industriales. Esto se debe particularmente a que, desde la modernidad, la inserción dentro del mercado de trabajo se constituye como una precondición para la integración social de las/os sujetas/os ${ }^{1}$ característica de las sociedades posrevolucionarias, donde el trabajo asalariado asume la forma dominante y se convierte en una forma singular de relación social y económica construida y situada históricamente (De la Serna, 2010).

Según Icart y Velasco (2016), las explicaciones económicas más tradicionales poco reflexionan sobre la realidad laboral femenina y, menos aún, sobre las múltiples relaciones de desigualdad y de dominio 
en las cuales las mismas se ven inmersas. Por ello, las teorías económicas feministas de la conciliación y de la ruptura constituyen un enfoque propicio para dar cuenta de ello. Conjuntamente, estos enfoques enfatizan y evidencian la relevancia económica de las mujeres en cuanto a la reproducción humana y social y exponen el rol fundamental de la tradicional división sexual del trabajo dentro del sistema capitalista y patriarcal, donde los roles sexuales y de género han derivado en la dependencia económica femenina, en su consecuente opresión y reclusión en el ámbito privado. De esta forma, estas teorías económicas feministas señalan de qué modo se delimita el ámbito público como el del trabajo productivo y asalariado, como un ámbito masculinizado y valorizado, en detrimento del trabajo de reproducción doméstica como feminizada, invisibilizada y desvalorizada para el capital, pero básica para la (re)producción de la vida.

Asimismo, estas teorías económicas feministas reconocen que el trabajo doméstico y de reproducción tiene un valor económico y social dentro de la economía convencional en las cuales, además, se pueden reconocer los cimientos sobre los cuales fue posible pensar las nociones de trabajo y de empleo en las sociedades industriales, es decir, a partir de la constitución de una división sexual del trabajo. Esto resulta ser la principal causa de la subordinación femenina; la primera fuente de opresión, de explotación económica y social capitalista, así como también la culminación de las relaciones diferenciales y desiguales entre varones y mujeres en el seno de la familia y del hogar. Así, se definen estas características como las que social, cultural y económicamente (re)producen, expresan y manifiestan la división sexual del trabajo(Icart y Velasco, 2016). La relevancia del trabajo de reproducción se convierte en el principal factor influyente de la doble carga de tareas a las que se encuentran sometidas las mujeres, comprometiendo así su desarrollo individual, profesional y laboral de forma diferenciada y desigual a la de los varones. Así, se puede evidenciar la trascendencia de las dicotomías: trabajo/no-trabajo, economía/no-economía, entre otras cuestiones.

Según los aportes de De la Serna (2010) y Ariño (2007), a lo largo de los siglos XX y XXI, las sociedades han vivido grandes transformaciones. Dentro del mundo laboral, se ha observado un considerable aumento de la fuerza de trabajo, particularmente la femenina, donde una de sus principales causas son las nuevas dinámicas económicas y familiares. Otros factores que entran en juego son la proliferación de la participación y la democratización de diversos ámbitos sociales, políticos y culturales. Se establecen, así, transformaciones relacionales y organizacionales dentro del mundo del trabajo y de la familia, donde trabajadoras y trabajadores se encuentran bajo nuevas regulaciones legales del mercado de trabajo; posibilitando mejoras en los niveles de vida, tanto para varones como para mujeres, incorporadas en el último siglo al mercado laboral regulado.

En línea con estas ideas, se realiza la presente investigación a nivel local. Se establece como principal objetivo explorar las formas en las que se expresa o concreta la desigualdad de género, social y económica dentro del ámbito privado y laboral de las jefas y los jefes de hogar ${ }^{2}$ de Tierra del Fuego, Antártida e Islas del Atlántico Sur (en adelante, AeIAS) durante el período 2003-2015. Como veremos más adelante, la zona geográfica es un área de vacancia para esta reflexión y el período viene dado por la disponibilidad de los datos en las fuentes existentes. Para ello, se identificaron los perfiles diferenciales de las jefaturas de hogar según sexo y estado civil, sus características socio-educativas, ingresos e inserción en el mercado de trabajo fueguino, las posibilidades de empleabilidad y sobre la participación de las jefaturas en el trabajo doméstico que evidenciaron diferencias y desigualdades de forma comparativa y relacional a partir de la manifestación de la división sexual del trabajo como principal fenómeno social, cultural, político y económico, configurador de estos perfiles socio-ocupacionales.

\section{Construcción TEóRico-Metodológica DeL OBJeto De ESTUdio}

El presente abordaje teórico delimita los parámetros conceptuales para la construcción del objeto de estudio y circunscribe las bases para el análisis del mercado de trabajo. En primera instancia, se hará referencia fundamental a la diferenciación conceptual entre las dicotomías: trabajo/no-trabajo y economía/ no-economía, inscriptas en relaciones de poder y dominio predominantemente capitalistas y patriarcales, 
para dar cuenta de la constitución de los roles femeninos y masculinos dentro del ámbito público-laboral y su relación al ámbito privado-doméstico.

Se retoman las nociones de trabajo y empleo teniendo en cuenta que no siempre fueron en sí mismas portadoras de identidad personal y/o de integración social. De esta manera, se entiende la noción de trabajo como aquella actividad coordinada de varones y mujeres, orientada a un fin específico para la (re)producción de bienes y servicios con fines y utilidad social, el cual requiere del uso de un esfuerzo psico-físico, cognitivo y/o de la implementación de capacidades afectivas y relacionales, así como de la puesta en práctica de determinadas calificaciones, experiencias y competencias profesionales de trabajadoras y trabajadores. La noción de empleo (asalariado), por su parte, es entendida como una relación histórica que vincula el trabajo de una persona con una organización dentro de un marco institucional y jurídico, que a su vez se constituye antes de su ingreso como aquella relación laboral que permanece en el tiempo y tiene un carácter mercantil; es decir, que se intercambia por un salario asignado individualmente, que goza de ciertas garantías jurídicas y de la protección social, normalizado mediante una clasificación resultante de reglas codificadas en los estatutos profesionales o en los convenios colectivos de trabajo. No todo trabajo es un empleo: es el caso del trabajo doméstico, en el cual no se percibe una remuneración individual por las tareas realizadas ya que, aunque dicho trabajo sea una actividad reconocida como socialmente útil, cuya duración semanal supera ampliamente la jornada máxima legal de trabajo, este no es valorizado dentro de los procesos productivos de bienes y servicios capitalizables (Neffa, 1999).

La conceptualización de género adquiere relevancia ya que no solo se lo considera como una categoría social y cultural sino también como una construcción social (re)producida y (re)adaptada a las necesidades funcionales de las sociedades modernas industrializadas, insertas en un sistema capitalista, industrial y patriarcal, que se mantiene como aquel eje dinamizador de desigualdades (Torns, 1995). ${ }^{3}$ Se establece, a su vez, que este tipo de relaciones se encuentran dentro de un dinamismo organizacional patriarcal basado en la primacía de los varones educados social y culturalmente en lo masculino y orientados hacia la producción de bienes y servicios, en detrimento de las mujeres, educadas social y culturalmente para las tareas reproductivas de la fuerza de trabajo. La primera es una actividad central para la reproducción de la sociedad y la última, una actividad desvalorizada en los propios términos de la producción capitalista (Torns, 1995). En este sentido, y bajo esta matriz binaria y heteronormada, ${ }^{4}$ la noción de trabajo de reproducción comprende aquellas actividades destinadas al cuidado del hogar y de la familia dentro del espacio hogareño y de la vivienda. A diferencia del trabajo doméstico, su espacio físico y simbólico no se circunscribe exclusivamente al hogar o ámbito doméstico, sino que su alcance se ve relacionado a todo aquello que tenga que ver con la gestión y el mantenimiento de la infraestructura del hogar y las derivadas de la atención y cuidado de los miembros de la familia, en la convicción de que todas esas actividades toman únicamente ese significado y esa concreción en las sociedades urbanas e industriales del mundo occidental (Carrasquer, Torns, Tejero y Romero, 1998).

De esta manera, se establece una relación dialéctica a partir de las nociones que trae aparejadas la división sexual del trabajo, entendiéndola como un proceso de segregación de roles entre varones y mujeres, donde dicha segregación compromete las posibilidades de ascenso, promoción y movilidad social de las mujeres, dada la doble carga social y cultural a la que se ven expuestas; en caso de desempeñarse laboralmente y en actividades de reproducción (Pautassi, 2007). Dicha dificultad se encuentra invisibilizada dado que todas las actividades que fueron históricamente asignadas como "femeninas" no se encuentran reglamentadas, sino que se (re)construyen y (re)producen según determinaciones sociales y/o culturales sobre la base de roles de género femenino, como madre, gestora, cuidadora y trabajadora doméstica no remunerada (Burin, 2004).

En lo que refiere al abordaje metodológico, se implementó una estrategia cuantitativa, que fue sustentada por datos del Instituto Nacional de Estadística y Censos (INDEC) desde la Encuesta Permanente de Hogares (EPH Continua); que para el Aglomerado 31 comprende el período 2003-2015, mediante el cuestionario individual, y la "Encuesta sobre el trabajo no remunerado y el uso del tiempo", del año 2013 llevada a cabo por el mismo organismo. En ellas, se presentan las magnitudes de diferentes variables según el sexo de las jefaturas de 
hogar y su aporte a la construcción de perfiles socio-ocupacionales, así como la evidencia de distintas formas de desigualdad de género, económicas, sociales y las magnitudes que adquiere la división sexual del trabajo en la composición de los hogares fueguinos. Las variables a analizar son Sexo de la Jefatura de Hogar, Estado Civil de la Jefa o Jefe de Hogar, Máximo Nivel de Estudios Alcanzados, Tasa de Actividad, Empleo y Desocupación, Mediana Anual de Ingresos Per cápita Familiares, Mediana Anual de Ingresos Individuales, Tiempo Diario Promedio Dedicado al Trabajo Doméstico, Tasa de Participación Diaria Dedicada al Trabajo Doméstico. Su alcance es meramente descriptivo, ya que si bien se registra una amplia variedad de trabajos de investigación nacionales e internacionales- que indagan sobre la división sexual del trabajo y su incidencia en la composición y dinámicas dentro del ámbito público-laboral y el ámbito privado-familiar, para el caso de la provincia de Tierra del Fuego, AeIAS no se registra este tipo de investigación y es en este sentido nuestro aporte.

\section{2. a. Perfiles diferenciales según sexo, estado civil y características socio-educativas}

A lo largo del período 2003-2015, dentro de los hogares fueguinos, se ha registra un incremento considerable de la participación relativa de jefaturas femeninas. Ello evidencia la transformación en las dinámicas familiares y las disímiles constituciones de los hogares. A comienzos del período, un 76,5\% de los hogares estaban compuestos por jefaturas masculinas (JM) y el restante $23,5 \%$ lo componían jefaturas femeninas (JF). Pero al finalizar dicho período, las JM decrecen a un $68,9 \%$ y las JF aumentan su participación a un 31,1\%, observándose en estas últimas un incremento de ocho (8) puntos porcentuales y una brecha de treinta y ocho (38) puntos porcentuales (Tabla $\mathrm{N}^{\circ} 1$ y Figura $\mathrm{N}^{\circ} 1$ ).

TABLA No1

Distribución porcentual de jefaturas de hogar según sexo. Tierra del Fuego, AeIAS. 2003-2015

\begin{tabular}{|c|c|c|c|}
\hline Año & Varón & Mujer & Total \\
\hline 2003 & $76,5 \%$ & $23,5 \%$ & $100,0 \%$ \\
\hline 2004 & $78,1 \%$ & $21,9 \%$ & $100,0 \%$ \\
\hline 2005 & $78,7 \%$ & $21,3 \%$ & $100,0 \%$ \\
\hline 2006 & $75,4 \%$ & $24,6 \%$ & $100,0 \%$ \\
\hline 2007 & $73,6 \%$ & $26,4 \%$ & $100,0 \%$ \\
\hline 2008 & $74,5 \%$ & $25,5 \%$ & $100,0 \%$ \\
\hline 2009 & $74,9 \%$ & $25,1 \%$ & $100,0 \%$ \\
\hline 2010 & $72,5 \%$ & $27,5 \%$ & $100,0 \%$ \\
\hline 2011 & $69,7 \%$ & $30,3 \%$ & $100,0 \%$ \\
\hline 2012 & $71,2 \%$ & $28,8 \%$ & $100,0 \%$ \\
\hline 2013 & $70,9 \%$ & $29,1 \%$ & $100,0 \%$ \\
\hline 2014 & $69,7 \%$ & $30,3 \%$ & $100,0 \%$ \\
\hline 2015 & $68,9 \%$ & $31,1 \%$ & $100,0 \%$ \\
\hline
\end{tabular}


FIGURA No 1

Distribución porcentual de hogar según sexo. Tierra del Fuego AeIAS. 2003-2015.

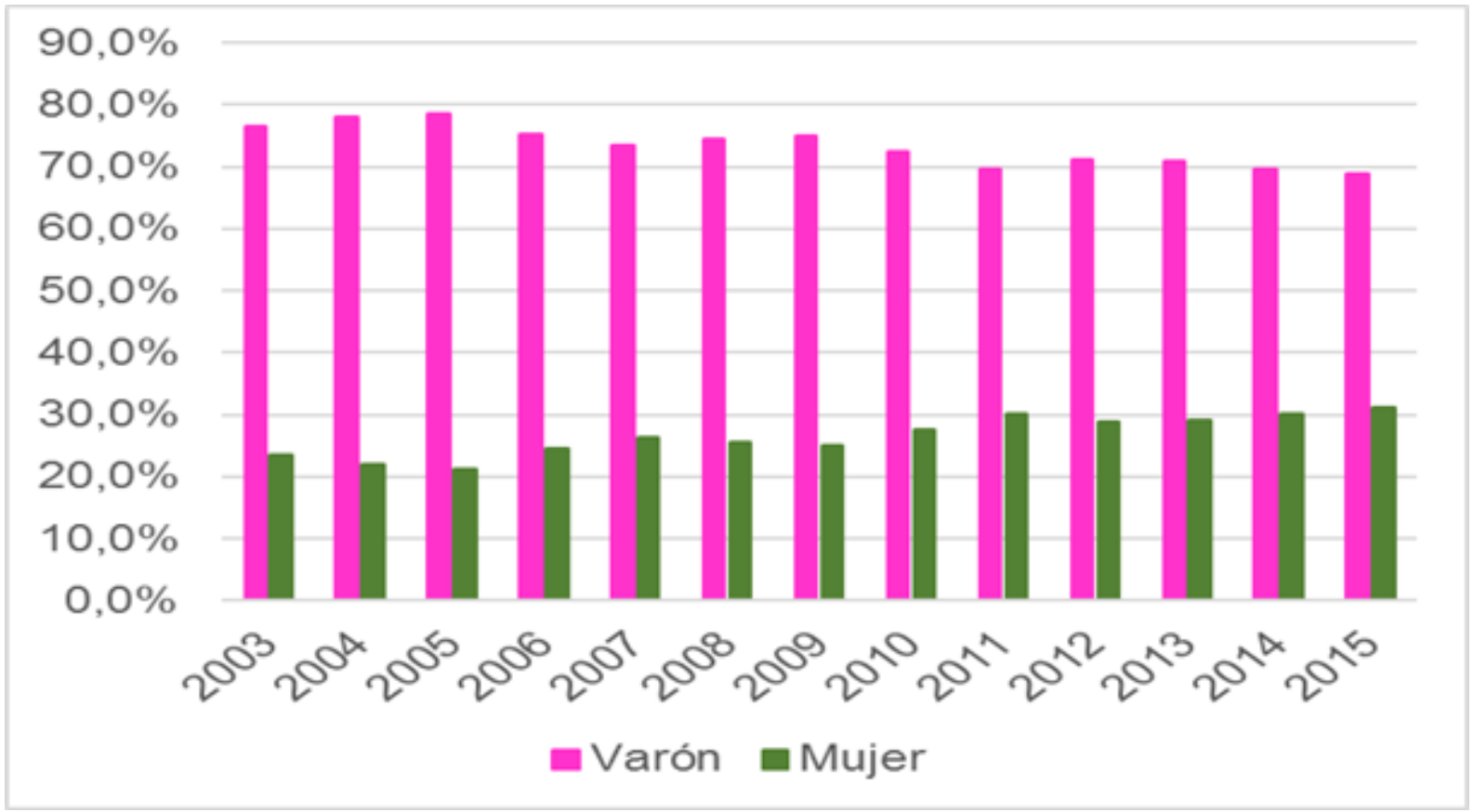

Fuente: Elaboración propia en base a datos de la EPH Continua. Aglomerado 31. Cuestionario 2003-2015.

En relación al estado civil, existe una predominancia de JM de varones casados, en detrimento de la participación de JF de mujeres casadas, siendo estas las que representan los menores aportes relativos sobre el total. En el año 2003, solo el 1,9\% de los hogares eran constituidos por jefas casadas, pero casi la mitad lo constituían jefes casados (49,3\%). Sin embargo, hacia el año 2015, estos últimos disminuyen su participación en casi veinte (20) puntos porcentuales $(29,6 \%)$, mientras las primeras la duplican, alcanzando una participación porcentual de 3,3\%. Asimismo, se identificó una variación similar en los comportamientos de los hogares constituidos por uniones de hecho entre convivientes. Si bien su participación relativa sobre el total es menor, la participación predominante es de varones unidos $(15,3 \%)$ y menor la participación de mujeres unidas (2,9\%). Aun así, al finalizar dicho período, se evidencia un aumento generalizado, pasando los primeros a constituir un $23,6 \%$ y las segundas un 7,6\% (Tabla №2 y Figura N ${ }^{\circ} 2$ ) 
TABLA No2

Distribución porcentual de jefatura de hogar según sexo y estado civil. Tierra del Fuego, AeIAS. 2003-2015

\begin{tabular}{|c|c|c|c|c|c|c|c|c|c|c|c|}
\hline \multirow{2}{*}{ Año } & \multicolumn{2}{|c|}{ Unido/a } & \multicolumn{2}{|c|}{ Casado/a } & \multicolumn{2}{c|}{$\begin{array}{c}\text { Separado/a o } \\
\text { divorciado/a }\end{array}$} & \multicolumn{2}{|c|}{ Viudo/a } & \multicolumn{2}{|c|}{ Soltero/a } & \multirow{2}{*}{ Total } \\
\cline { 2 - 11 } & Varón & Mujer & Varón & Mujer & Varón & Mujer & Varón & Mujer & Varón & Mujer & \\
\hline 2003 & $15,3 \%$ & $2,9 \%$ & $49,3 \%$ & $1,9 \%$ & $4,5 \%$ & $7,9 \%$ & $2,4 \%$ & $4,5 \%$ & $5,0 \%$ & $6,3 \%$ & $100 \%$ \\
\hline 2004 & $17,6 \%$ & $2,0 \%$ & $48,7 \%$ & $1,6 \%$ & $4,1 \%$ & $9,2 \%$ & $2,0 \%$ & $4,1 \%$ & $5,7 \%$ & $5,1 \%$ & $100 \%$ \\
\hline 2005 & $19,3 \%$ & $2,1 \%$ & $45,6 \%$ & $1,2 \%$ & $4,4 \%$ & $8,3 \%$ & $1,7 \%$ & $3,7 \%$ & $7,8 \%$ & $6,0 \%$ & $100 \%$ \\
\hline 2006 & $19,0 \%$ & $3,6 \%$ & $44,7 \%$ & $1,3 \%$ & $4,1 \%$ & $9,5 \%$ & $0,9 \%$ & $3,7 \%$ & $6,7 \%$ & $6,5 \%$ & $100 \%$ \\
\hline 2007 & $21,2 \%$ & $4,8 \%$ & $41,0 \%$ & $1,5 \%$ & $4,4 \%$ & $9,2 \%$ & $1,3 \%$ & $4,5 \%$ & $5,7 \%$ & $6,4 \%$ & $100 \%$ \\
\hline 2008 & $20,1 \%$ & $4,5 \%$ & $42,9 \%$ & $2,3 \%$ & $3,8 \%$ & $7,4 \%$ & $1,0 \%$ & $4,3 \%$ & $6,7 \%$ & $7,0 \%$ & $100 \%$ \\
\hline 2009 & $19,6 \%$ & $4,2 \%$ & $42,0 \%$ & $2,3 \%$ & $4,7 \%$ & $7,2 \%$ & $1,2 \%$ & $3,9 \%$ & $7,4 \%$ & $7,5 \%$ & $100 \%$ \\
\hline 2010 & $19,6 \%$ & $5,1 \%$ & $39,8 \%$ & $2,6 \%$ & $4,1 \%$ & $6,8 \%$ & $1,7 \%$ & $5,1 \%$ & $7,4 \%$ & $7,9 \%$ & $100 \%$ \\
\hline 2011 & $20,4 \%$ & $4,7 \%$ & $36,7 \%$ & $3,5 \%$ & $3,0 \%$ & $9,9 \%$ & $0,8 \%$ & $3,7 \%$ & $8,7 \%$ & $8,4 \%$ & $100 \%$ \\
\hline 2012 & $22,9 \%$ & $3,3 \%$ & $35,7 \%$ & $3,3 \%$ & $2,6 \%$ & $9,4 \%$ & $1,2 \%$ & $3,8 \%$ & $8,9 \%$ & $9,0 \%$ & $100 \%$ \\
\hline 2013 & $25,5 \%$ & $5,1 \%$ & $31,0 \%$ & $2,5 \%$ & $3,9 \%$ & $8,1 \%$ & $1,6 \%$ & $3,6 \%$ & $8,8 \%$ & $9,9 \%$ & $100 \%$ \\
\hline 2014 & $21,3 \%$ & $5,5 \%$ & $32,8 \%$ & $2,9 \%$ & $5,0 \%$ & $8,3 \%$ & $1,5 \%$ & $3,2 \%$ & $9,2 \%$ & $10,4 \%$ & $100 \%$ \\
\hline 2015 & $23,6 \%$ & $7,6 \%$ & $29,6 \%$ & $3,3 \%$ & $4,5 \%$ & $6,3 \%$ & $1,3 \%$ & $4,4 \%$ & $9,9 \%$ & $9,5 \%$ & $100 \%$ \\
\hline
\end{tabular}

Fuente: Elaboración propia en base a datos de la EPH Continua. Aglomerado 31. Cuestionario individual.2003-2015.

Es importante destacar no sólo la predominancia de JM, sino también el progresivo traspaso de familias nucleares, como modelo hegemónico, hacia un proceso de diversificación familiar y a una modificación del rol femenino fuera y dentro del ámbito privado-familiar, dando como resultado una creciente heterogeneidad estructural socio-económica y sociodemográfica de los hogares; particularmente en los hogares con JF. Según Ariño (2007), estas transformaciones son posibles porque involucran fenómenos como la mayor aceptación social de la sexualidad, la reivindicación de la autonomía individual, el uso de los métodos anticonceptivos y una mayor simetría en la relación entre cónyuges, entre otras. Pero, en términos de Torns (1995), esta mayor democratización en las relaciones conyugales y los cambios en el rol femenino, dentro y fuera del ámbito privado, supone una doble carga por el acceso al mercado de trabajo. De acuerdo a lo establecido política y socio-culturalmente por la división sexual del trabajo y la heteronormatividad hegemónica dentro de la organización familiar -agravada por la responsabilidad de ser cabezas de familia- las condiciones laborales y de empleabilidad se vuelven desventajosas, por lo tanto, se encuentran relegadas a la necesidad de mayores y múltiples credenciales educativas y/o características profesionales. 
FIGURA $\mathrm{N}^{\circ} 2$

Distribución porcentual de jefatura según sexo y estado civil. Tierra del Fuego, AeIAS. 2003-2015.

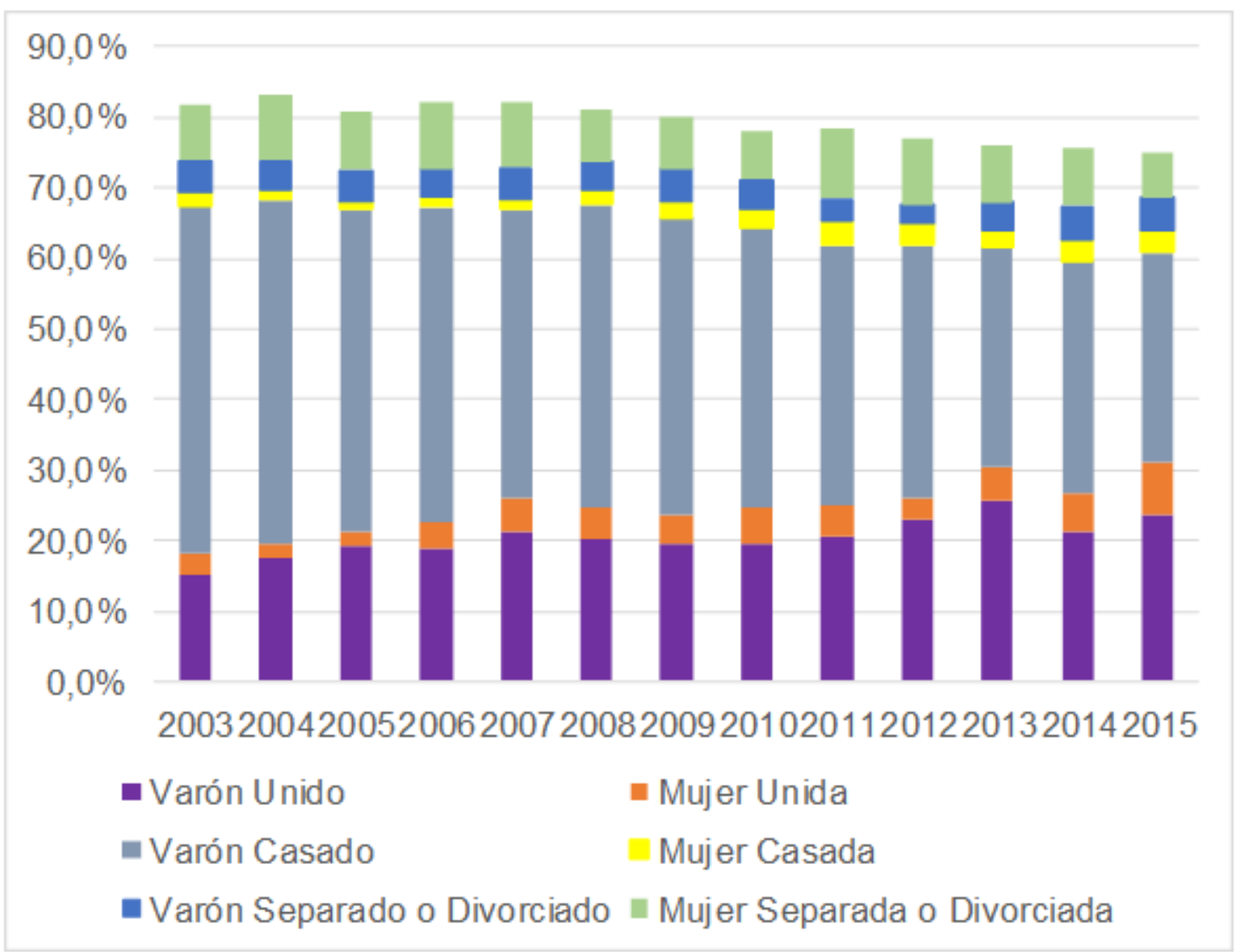

Fuente: Elaboración propia en base a datos de la EPH Continua. Aglomerado 31. Cuestionario individual.2003-2015.

FIGURA No3

Tasa de actividad de jefatura de hogar según sexo. Tierra del Fuego AeIAS. 2003-2015.

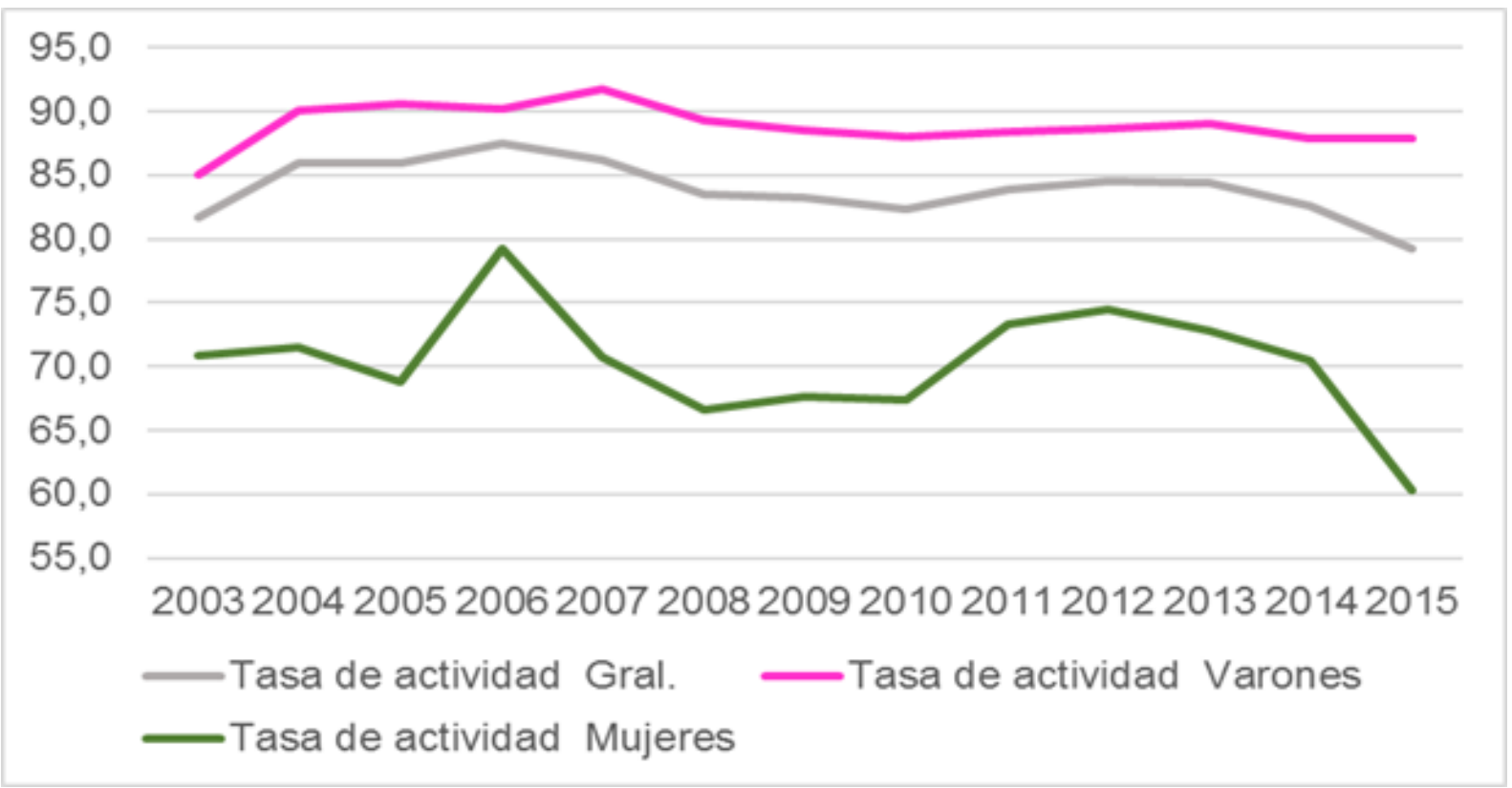

Fuente: Elaboración propia en base a datos de la EPH Continua. Aglomerado 31. Cuestionario individual.2003-2015. 
Entre el período 2003-2015, se observa que, efectivamente, dentro de la participación relativa total, las JF son las que han incrementado mayormente sus credenciales educativas; particularmente en la educación secundaria, de $11,8 \%$ a $13 \%$ (JM: 35,4\% a 35\%), y en la educación universitaria, de 4,3\% a 11\% (JM: 19,8\% a 18\%) (Tabla $\mathrm{N}^{\circ} 3$ ). A medida que transcurre el tiempo, las JF, en conjunto, adquieren un perfil más profesionalizado, dado que los porcentajes relativos de mujeres jefas con niveles educativos universitarios aumentan $(18,1 \%$ a $35 \%)$ en detrimento de los niveles educativos hasta el nivel primario $(30,7 \%$ a $23,7 \%)$ y el nivel secundario (50,4\% a 41\%), los cuales disminuyen (Tabla $\mathrm{N}^{\circ} 4$ ). En contraposición, en los hogares con $\mathrm{JM}$, a lo largo del período, se produce un reducido crecimiento en la profesionalización: el nivel universitario crece $(25,8 \%$ a $26,2 \%)$, mientras que el nivel secundario aumenta de manera más notoria $(46,3 \%$ a $51 \%)$ y el nivel primario disminuye (27,2\% a 22,6\%), (Tabla $\mathrm{N}^{\circ} 5$ ).

\section{TABLA No3}

Distribución porcentual de jefatura de hogar según sexo y máximo nivel educativo alcanzado. Tierra del Fuego, AeIAS. 2003-2015.

\begin{tabular}{|c|c|c|c|c|c|c|c|c|c|}
\hline \multirow{2}{*}{ Año } & \multicolumn{2}{|c|}{$\begin{array}{c}\text { Sin } \\
\text { instrucción }\end{array}$} & \multicolumn{2}{c|}{$\begin{array}{c}\text { Hasta } \\
\text { primaria } \\
\text { completa }\end{array}$} & \multicolumn{2}{c|}{$\begin{array}{c}\text { Hasta } \\
\text { secundaria } \\
\text { completa }\end{array}$} & \multicolumn{2}{c|}{$\begin{array}{c}\text { Hasta } \\
\text { universitaria } \\
\text { completa }\end{array}$} & \multirow{2}{*}{ Total } \\
\cline { 2 - 9 } & Varón & Mujer & Varón & Mujer & Varón & Mujer & Varón & Mujer & \\
\hline 2003 & $0,5 \%$ & $0,2 \%$ & $20,8 \%$ & $7,2 \%$ & $35,4 \%$ & $11,8 \%$ & $19,8 \%$ & $4,3 \%$ & $100 \%$ \\
\hline 2015 & $0 \%$ & $0 \%$ & $16 \%$ & $7 \%$ & $35 \%$ & $13 \%$ & $18 \%$ & $11 \%$ & $100 \%$ \\
\hline
\end{tabular}

Fuente: Elaboración propia en base a datos de la EPH Continua. Aglomerado 31. Cuestionario individual.2003-2015.

TABLA N4

Distribución porcentual de jefaturas femeninas según máximo nivel educativo alcanzado. Tierra del Fuego, AeIAS. 2003-2015.

\begin{tabular}{|c|c|c|c|c|c|c|c|c|c|c|}
\hline \multirow{2}{*}{ Año } & \multicolumn{2}{|c|}{$\begin{array}{c}\text { Sin instrucción } \\
\end{array}$} & \multicolumn{2}{|c|}{$\begin{array}{c}\text { Hasta primaria } \\
\text { completa }\end{array}$} & \multicolumn{2}{c|}{$\begin{array}{c}\text { Hasta } \\
\text { secundaria } \\
\text { completa }\end{array}$} & $\begin{array}{c}\text { Hasta } \\
\text { universitaria } \\
\text { completa }\end{array}$ & \multicolumn{2}{|c|}{ Total } \\
\cline { 2 - 11 } & Abs & $\%$ & Abs & $\%$ & Abs & $\%$ & Abs & $\%$ & Abs & $\%$ \\
\hline 2003 & 97 & $0,7 \%$ & 3.998 & $30,7 \%$ & 6.565 & $50,4 \%$ & 2.357 & $18,1 \%$ & 13.017 & $100 \%$ \\
\hline 2015 & 86 & $0,3 \%$ & 6.942 & $23,7 \%$ & 11.997 & $41,0 \%$ & 10.228 & $35,0 \%$ & 29.253 & $100 \%$ \\
\hline
\end{tabular}


TABLA N०5

Distribución porcentual de jefaturas masculinas según máximo nivel educativo alcanzado. Tierra del Fuego, AeIAS. 2003-2015.

\begin{tabular}{|c|c|c|c|c|c|c|c|c|c|c|}
\hline \multirow{2}{*}{ Año } & \multicolumn{2}{|c|}{$\begin{array}{c}\text { Sin instrucción } \\
\end{array}$} & \multicolumn{2}{|c|}{$\begin{array}{c}\text { Hasta primaria } \\
\text { completa }\end{array}$} & \multicolumn{2}{c|}{$\begin{array}{c}\text { Hasta } \\
\text { secundaria } \\
\text { completa }\end{array}$} & \multicolumn{2}{c|}{$\begin{array}{c}\text { Hasta } \\
\text { universitaria } \\
\text { completa }\end{array}$} & \multicolumn{2}{|c|}{ Total } \\
\cline { 2 - 11 } & Abs & $\%$ & Abs & $\%$ & Abs & $\%$ & Abs & $\%$ & Abs & $\%$ \\
\hline 2003 & 292 & $0,7 \%$ & 11.527 & $27,2 \%$ & 19.651 & $46,3 \%$ & 10.965 & $25,8 \%$ & 42.435 & $100 \%$ \\
\hline 2015 & 201 & $0,3 \%$ & 14.621 & $22,6 \%$ & 33.036 & $51,0 \%$ & 16.948 & $26,2 \%$ & 64.806 & $100 \%$ \\
\hline
\end{tabular}

Fuente: Elaboración propia en base a datos de la EPH Continua. Aglomerado 31. Cuestionario individual.2003-2015.

\section{2. b. División sexual del trabajo, trabajo doméstico, tasa de participación y horas dedicadas según jefatura por sexo}

La constitución familiar es una de las principales formas organizacionales sobre la que se construyen los cimientos que permiten la reproducción de los roles de género en la sociedad. El contrato social-sexual (Pateman, 1995) permite el desarrollo de los sujetos masculinos en el ámbito público e invisibiliza el ámbito privado, donde se desempeñan mayormente las sujetas femeninas. Aquella doble carga femenina se representa por la asignación de las tareas de reproducción en el hogar y fuera del hogar, transformándose en el factor explicativo de las desigualdades respecto a las posibilidades de empleabilidad femenina respecto de la masculina. Allí, radica el principal factor en la participación marginal masculina respecto a las tareas de reproducción y en la diferencial y desigual distribución de tareas doméstica entre varones y las mujeres. La doble subordinación femenina como resultado de la coexistencia de sistemas que se conjugan y componen las relaciones de desigualdad y dominación: el sistema patriarcal y el sistema capitalista determinan y norman el uso del tiempo femenino y su consecuente parcialización en actividades laborales empleadas en el ámbito público (Torns, 1995).

En relación con la participación diaria respecto al trabajo doméstico no remunerado, en lo que respecta a las jefas y los jefes de hogar en Tierra del Fuego, la tasa de participación provincial promedio en ambos casos es superior al promedio nacional. Al ser la participación de JM de un 79,5\% (65\% promedio total nacional) y para las JF un 91,6\% (89\% promedio total del país), se infiere que los jefes varones fueguinos están más involucrados en las actividades domésticas no remuneradas que el promedio total, aunque los niveles de participación femenina son significativamente mayores a estos, con una brecha de alrededor de doce (12) puntos porcentuales. En relación a la crianza y a la participación de las hijas y los hijos así como de otras personas convivientes, la participación femenina sigue siendo mayor y por lo tanto desigual (Tabla $\mathrm{N}^{\circ}$ 6).

El tiempo diario en horas dedicado al trabajo doméstico no remunerado también presenta significativas diferencias. En relación con las jefas y los jefes de hogar se puede ver que el promedio de horas invertidas son superiores al promedio nacional para ambos grupos, siendo para las primeras un total de 6,6 horas diarias (5,3 horas para el total nacional) y, para los segundos, un total de 4,9 horas diarias (3,6 horas para el total nacional). Ello permite calcular alrededor de dos horas promedio más lo que las mujeres jefas se "encargan" de las tareas del hogar en relación con las que ocupan los varones jefes. En segunda instancia, en lo que refiere a la situación de las y los cónyuges, tiene un comportamiento similar siendo los valores promedio provinciales superiores al promedio nacional; varones 3,7 horas diarias promedio $(3,4$ horas para el total nacional) y 9,6 horas diarias promedio para las mujeres (7,6 para el total nacional). Por lo tanto, ante esta 
dicotomía varón/mujer en su relación de jefas y jefes y cónyuges, -presuponiendo que nos encontramos ante relaciones heterosexuales y heteronormadas-, si bien la participación masculina es superior al promedio total nacional, las diferencias se encuentran con relación a la participación de sus cónyuges, dado que la participación femenina ronda las 10 horas diarias de dedicación como cónyuge, a diferencia de los cónyuges varones que rondan aproximadamente las 4 horas diarias. Es decir, es evidente una brecha en la comparativa entre cónyuges y entre parejas heterosexuales donde las mujeres son jefas de hogar (Tabla N ${ }^{\circ} 7$ ).

Es fundamental hacer énfasis en lo que implica la asignación política, social, cultural y hasta económica de los roles de género, predeterminando una constitución y (re)construcción de varón-masculino y mujerfemenina, respecto a sus papeles en el ámbito público y privado (Torns, 1995). A partir de lo expuesto anteriormente, se evidencia una mayor precarización de la economía femenina (Icart y Velasco, 2016).

TABLA No 6

Tasa de participación diaria dedicada al trabajo doméstico no remunerado de la población de 18 años y más por sexo y relación de parentesco con la/el jefa/e de hogar. Total nacional urbano y Provincia de Tierra del Fuego, AeIAS. $3^{\circ}$ Trimestre del año 2013.

\begin{tabular}{|c|l|l|l|l|l|l|l|l|}
\hline \multirow{2}{*}{\begin{tabular}{c} 
Provincia \\
\cline { 2 - 9 }
\end{tabular}} & \multicolumn{3}{|c|}{ Jefe / a } & \multicolumn{2}{c|}{ Cónyuge / Pareja } & $\begin{array}{c}\text { Hijo/a / Hijastro/a / } \\
\text { Yerno / Nuera }\end{array}$ & \multicolumn{2}{c|}{ Otros familiares } \\
\cline { 2 - 9 } & Varones & Mujeres & Varones & Mujeres & Varones & Mujeres & Varones & Mujeres \\
\hline $\begin{array}{c}\text { Total nacional } \\
\text { urbano }\end{array}$ & 65,0 & 89,0 & 54,2 & 95,3 & 43,4 & 79,8 & 49,7 & 72,9 \\
\hline $\begin{array}{c}\text { Tierra del } \\
\text { Fuego, AelAS. }\end{array}$ & 79,5 & 91,6 & 76,9 & 94,5 & 64,4 & 90,2 & 74,6 & 73,6 \\
\hline
\end{tabular}

Fuente: Elaboración propia en base a datos del INDEC. Encuesta sobre Trabajo No Remunerado y Uso del Tiempo. Tasa de participación y tiempo promedio diario dedicado al trabajo doméstico no remunerado de la población de 18 años y más por sexo y relación de parentesco con el jefe de hogar, según provincia. Total nacional urbano - Tercer trimestre de 2013.

TABLA No7

Tiempo diario promedio dedicado al trabajo doméstico no remunerado de la población de 18 años y más por sexo y relación de parentesco con la/el jefa/e de hogar. Total nacional urbano y Provincia de Tierra del Fuego, AeIAS. $3^{\circ}$ Trimestre del año 2013.

\begin{tabular}{|c|c|c|c|c|c|c|c|c|}
\hline \multirow{2}{*}{ Provincia } & \multicolumn{2}{|c|}{ Jefe / a } & \multicolumn{2}{c|}{ Cónyuge / Pareja } & \multicolumn{2}{c|}{$\begin{array}{r}\text { Hijo/a / Hijastro/a / } \\
\text { Yerno / Nuera }\end{array}$} & \multicolumn{2}{c|}{ Otros familiares } \\
\cline { 2 - 9 } & Varones & Mujeres & Varones & Mujeres & Varones & Mujeres & Varones & Mujeres \\
\hline $\begin{array}{c}\text { Total nacional } \\
\text { urbano }\end{array}$ & 3,6 & 5,3 & 3,4 & 7,6 & 2,7 & 5,5 & 2,6 & 5,0 \\
\hline $\begin{array}{c}\text { Tierra del } \\
\text { Fuego, AelAS }\end{array}$ & 4,9 & 6,6 & 3,7 & 9,6 & 4,1 & 6,7 & 3,7 & 5,4 \\
\hline
\end{tabular}

Fuente: Elaboración propia en base a datos del INDEC. Encuesta sobre Trabajo. No Remunerado y Uso del Tiempo. Tasa de participación y tiempo promedio diario dedicado al trabajo doméstico no remunerado de la población de 18 años y más por sexo y relación de parentesco con el jefe de hogar, según provincia. Total nacional urbano. Tercer trimestre de 2013. 


\section{2. c. Principales indicadores del mercado de trabajo fueguino. Ingresos y posibilidades de empleabilidad femenina}

Desde el año 2003, en Argentina, se vive un contexto económico caracterizado por una reactivación de la industria y la profundización del modelo agroexportador, el cual generó múltiples transformaciones en lo que refiere a la economía de la sociedad y sus estilos de vida, determinando de esta manera una amplitud para el acceso al mercado de trabajo (Basualdo, 2011).

A partir de los principales indicadores del mercado de trabajo, se constata que, efectivamente, durante el período 2003-2015, los niveles de actividad general de las jefaturas pasaron de $81,8 \%$ a $79,3 \%$, siendo constante la superioridad porcentual promedio para las JM $(85,1 \%$ a $87,8 \%)$, mientras que para las JF sus niveles de actividad han disminuido (70,9\% a 60,3\%) pasando de una diferencia de catorce (14) puntos porcentuales a dieciocho (18) puntos porcentuales (Tabla $\mathrm{N}^{\circ} 8$ y Figura $\mathrm{N}^{\circ} 3$ ).

Respecto de las posibilidades de empleabilidad, la Tasa de Empleo promedio pasó de 77,1\% a 77,4\%, manteniéndose una predominancia en la empleabilidad masculina $(81 \%$ a $86,1 \%)$ y una baja en la femenina (64,6\% a 58,2\%). Es decir, se constata una brecha de casi dieciocho (18) puntos porcentuales en 2003 a veintiocho (28) puntos porcentuales en 2015 (Tabla $\mathrm{N}^{\circ} 8$ y Figura $\mathrm{N}^{\circ} 4$ ). En lo referido al desempleo de las jefaturas, sus niveles pasaron de 5,6\% a 2,3\%, presentándose para las JM valores inferiores al promedio total $(4,8 \%$ a $1,9 \%)$ y para las JF los valores porcentuales casi duplican los valores porcentuales de los primeros $(8,9 \%$ a 3,4\%), es decir, que aunque la tasa de desempleo general ha descendido en casi tres (3) puntos y medio porcentuales, la población que se encuentra en mayores proporciones en busca de empleo o disponible para trabajar, es la femenina (Tabla $\mathrm{N}^{\circ} 8$ y Figura $\mathrm{N}^{\circ}$ ).

TABLA N ${ }^{\circ} 8$

Tasa de actividad, empleo y desocupación de jefatura de

hogar según sexo. Tierra del Fuego, AeIAS. 2003-2015.

\begin{tabular}{|c|c|c|c|c|c|c|c|c|c|}
\hline \multirow{2}{*}{ Año } & \multicolumn{3}{|c|}{ Tasa de actividad } & \multicolumn{3}{c|}{ Tasa de empleo } & \multicolumn{2}{c|}{ Tasa de desocupación } \\
\cline { 2 - 10 } & Gral. & Varones & Mujeres & Gral. & Varones & Mujeres & Gral. & Varones & Mujeres \\
\hline 2003 & 81,8 & 85,1 & 70,9 & 77,1 & 81,0 & 64,6 & 5,6 & 4,8 & 8,9 \\
\hline 2004 & 86,0 & 90,1 & 71,5 & 81,8 & 86,0 & 66,9 & 4,9 & 4,6 & 6,5 \\
\hline 2005 & 85,9 & 90,5 & 68,8 & 82,7 & 87,4 & 65,0 & 3,8 & 3,4 & 5,4 \\
\hline 2006 & 87,5 & 90,2 & 79,2 & 84,0 & 87,5 & 73,3 & 4,0 & 3,1 & 7,5 \\
\hline 2007 & 86,2 & 91,7 & 70,7 & 83,4 & 89,4 & 66,8 & 3,2 & 2,5 & 5,6 \\
\hline 2008 & 83,5 & 89,2 & 66,6 & 81,0 & 87,1 & 63,4 & 2,9 & 2,4 & 4,9 \\
\hline 2009 & 83,3 & 88,5 & 67,6 & 78,3 & 83,3 & 63,5 & 5,9 & 5,9 & 6,0 \\
\hline 2010 & 82,4 & 88,1 & 67,4 & 79,5 & 85,4 & 63,8 & 3,5 & 3,0 & 5,3 \\
\hline 2011 & 83,8 & 88,4 & 73,3 & 81,6 & 86,8 & 69,5 & 2,7 & 1,8 & 5,1 \\
\hline 2012 & 84,6 & 88,6 & 74,5 & 81,9 & 86,2 & 71,0 & 3,2 & 2,7 & 4,7 \\
\hline 2013 & 84,4 & 89,1 & 72,8 & 81,6 & 86,4 & 69,7 & 3,3 & 3,0 & 4,3 \\
\hline 2014 & 82,6 & 87,9 & 70,5 & 79,9 & 85,2 & 67,9 & 3,3 & 3,1 & 3,6 \\
\hline 2015 & 79,3 & 87,8 & 60,3 & 77,4 & 86,1 & 58,2 & 2,3 & 1,9 & 3,4 \\
\hline
\end{tabular}


Fuente: Elaboración propia en base a datos de la EPH Continua. Aglomerado 31. Cuestionario individual.2003-2015.

FIGURA N 5

Tasa de desocupación de jefatura de hogar según sexo. Tierra del Fuego, AeIAS. 2003-2015.

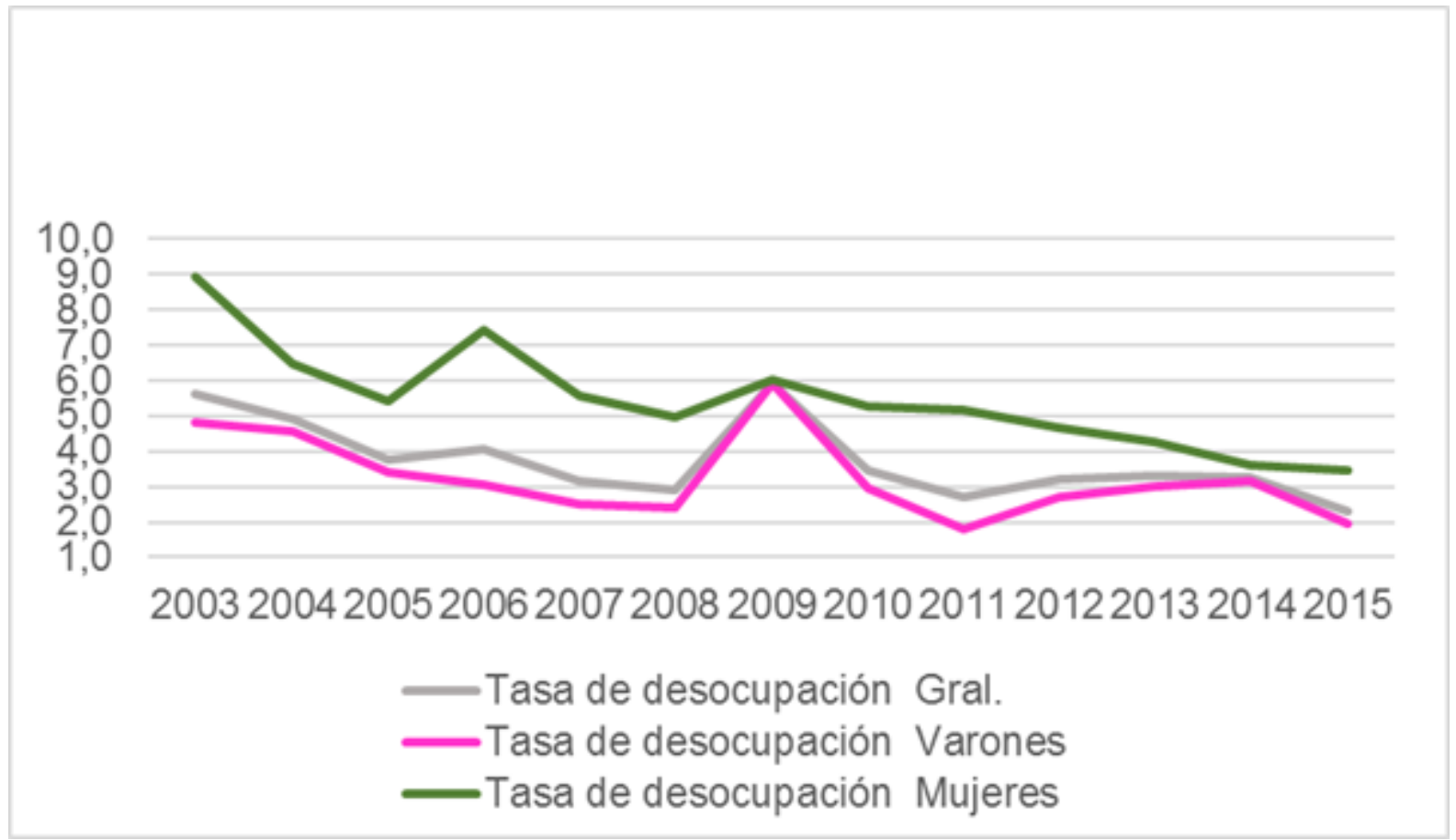

Fuente: Elaboración propia en base a datos de la EPH Continua. Aglomerado 31. Cuestionario individual. 2003-2015.

En un comienzo hemos establecido un aumento participativo de jefaturas femeninas, una mayor democratización de las relaciones conyugales, una heterogeneización en la organización familiar y una mayor adquisición de credenciales en detrimento de los varones, al momento de analizar el mercado de trabajo respecto de la inserción de JF. Se puede afirmar, entonces, que para las JF se mantienen amplias desigualdades ya que el incremento de la tasa de actividad no ha impedido que el desempleo siga manteniendo una predominancia femenina, lo que evidencia que, si bien este disminuye, sus características estructurales aún persisten. 
FIGURA N ${ }^{\circ} 4$

Tasa de empleo de jefatura de hogar según sexo. Tierra del Fuego, AeIAS

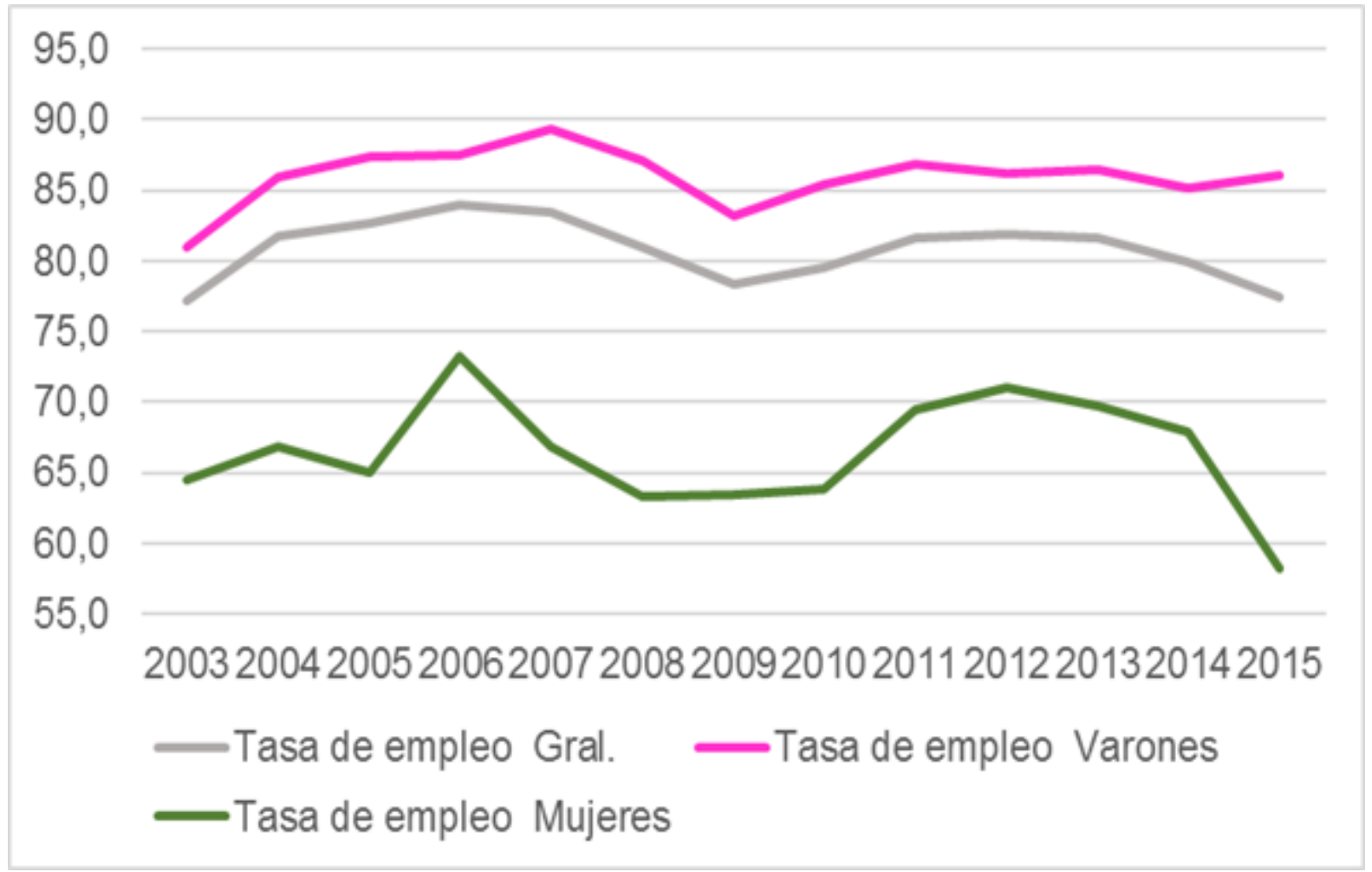

Fuente: Elaboración propia en base a datos de la EPH Continua. Aglomerado 31. Cuestionario individual. 2003-2015.

Así también, otra de las múltiples formas de expresión de desigualdad de género dentro del mercado de trabajo se vio expresada en las brechas salariales. Según Torrado (1995), los hogares con mayores niveles de pobreza por ingresos y en condiciones de vulnerabilidad suelen estar encabezados por una mujer, principal sostén económico de familia. A partir del cálculo del promedio de ingresos mensuales laborales y no laborales, se pudo evidenciar que las JM poseen ingresos superiores a las JF, viéndolo como un rasgo estructural persistente que se acrecienta a medida que transcurre dicho periodo. Los varones pasaron de percibir un promedio de casi $\$ 1.220$ pesos a $\$ 17.070$, y las mujeres alrededor de $\$ 790$ pesos a $\$ 12.090$. Vale decir, al comenzar el periodo las mujeres cobraban alrededor del $64 \%$ de lo que cobraban los varones - alrededor del $71 \%$ - (Tabla Nº y Figura N6). 
TABLA $\mathrm{N}^{\circ} 9$

Mediana anual de ingresos individuales (Mens.) laborales y no laborales, de jefatura de hogar según sexo. Tierra del Fuego, AeIAS. 2003-2015.

\begin{tabular}{|c|c|cc|c|}
\hline Año & Varón & \multicolumn{2}{|c|}{ Mujer } & \multicolumn{2}{c|}{ Diferencia } \\
\hline 2003 & $\$ 1.217,00$ & $\$$ & 790,00 & $\$ 427,00$ \\
\hline 2004 & $\$ 1.382,00$ & $\$ 1.059,00$ & $\$ 323,00$ \\
\hline 2005 & $\$ 1.927,00$ & $\$ 11.260,00$ & $\$ 667,00$ \\
\hline 2006 & $\$ 2.538,00$ & $\$ 11.695,00$ & $\$ 843,00$ \\
\hline 2007 & $\$ 3.126,00$ & $\$ 2.140,00$ & $\$ 986,00$ \\
\hline 2008 & $\$ 3.834,00$ & $\$ 2.756,00$ & $\$ 1.078,00$ \\
\hline 2009 & $\$ 4.368,00$ & $\$ 3.175,00$ & $\$ 1.193,00$ \\
\hline 2010 & $\$ 5.250,00$ & $\$ 3.632,00$ & $\$ 1.618,00$ \\
\hline 2011 & $\$ 6.197,00$ & $\$ 44.850,00$ & $\$ 1.347,00$ \\
\hline 2012 & $\$ 8.437,00$ & $\$ 6.635,00$ & $\$ 1.802,00$ \\
\hline 2013 & $\$ 11.089,00$ & $\$ 8.489,00$ & $\$ 2.600,00$ \\
\hline 2014 & $\$ 13.648,00$ & $\$ 10.660,00$ & $\$ 2.988,00$ \\
\hline 2015 & $\$ 17.071,00$ & $\$ 12.094,00$ & $\$ 4.977,00$ \\
\hline
\end{tabular}


FIGURA $\mathrm{N}^{\circ} 6$

Mediana anual de ingresos individuales (Mens.) laborales y no laborales, de jefatura de hogar según sexo. Tierra del Fuego AeIAS. 2003-2015.

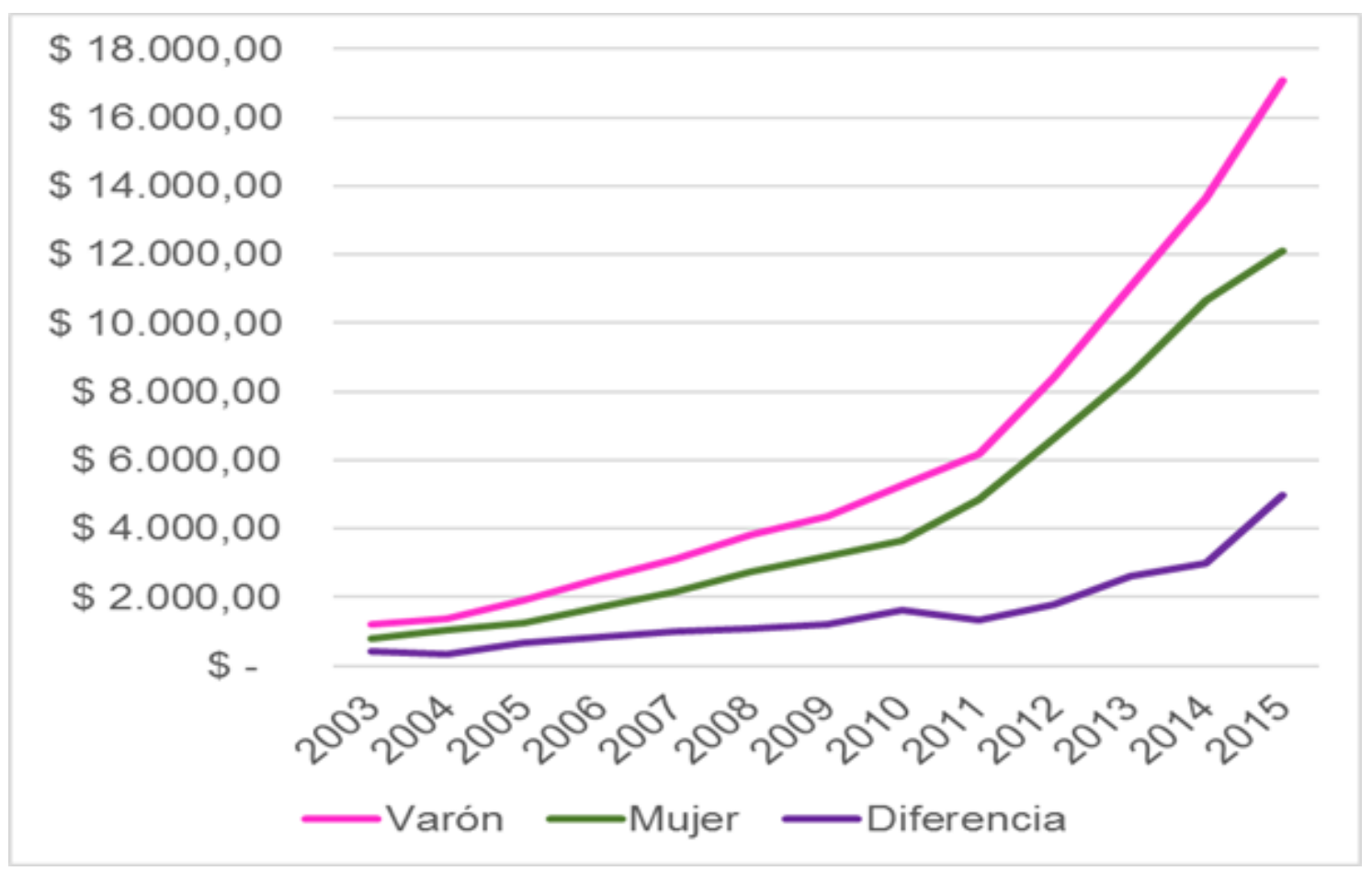

Fuente: Elaboración propia en base a datos de la EPH Continua. Aglomerado 31. Cuestionario individual. 2003-2015.

$\mathrm{Al}$ percibir menos ingresos, se observa una desigualdad persistente en las distribuciones. A lo largo del periodo, los hogares con JM pasaron de percibir alrededor de $\$ 400$ pesos mensuales per-cápita a casi $\$ 8.170$, mientras que las/os integrantes de los hogares con JF pasaron de $\$ 300$ pesos a $\$ 7.500$. Manifestando que al comenzar el período cada integrante de los hogares de JF percibían un 75\% de lo que percibían los de JM y al finalizar dicho período alcanzaron a percibir casi un $92 \%$ (Tabla $\mathrm{N}^{\circ} 10$ y Figura $\mathrm{N}^{\circ} 7$ ). 
FIGURA $\mathrm{N}^{\mathrm{0}} 7$

Mediana anual de ingresos per cápita familias (Mens.) de jefatura de hogar según sexo. Tierra del Fuego, AeIAS. 2003- 2015.

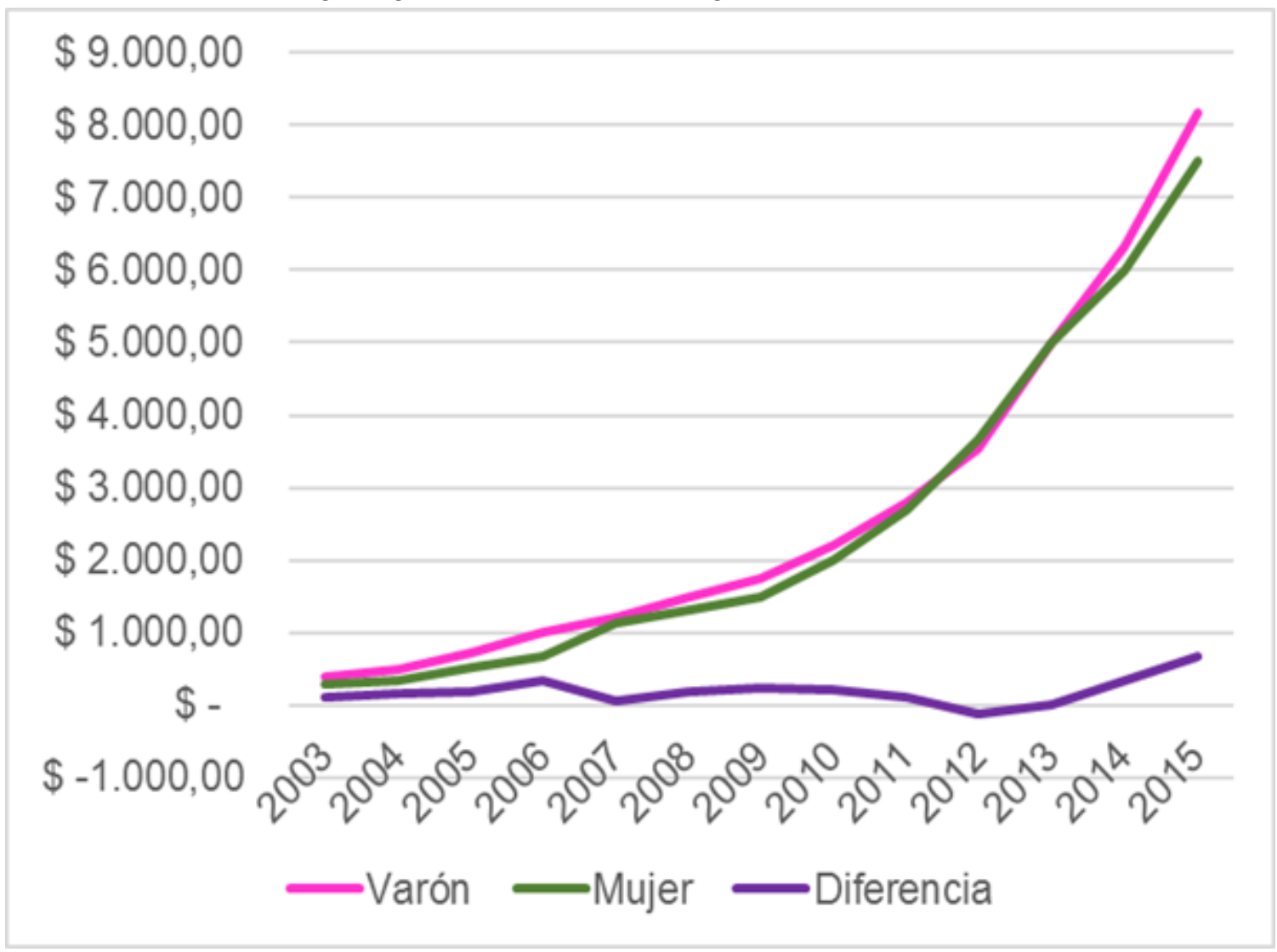

Fuente: Elaboración propia en base a datos de la EPH Continua. Aglomerado 31. Cuestionario individual.2003-2015. 
TABLA Nº

Mediana anual de ingresos per capita familiares (Mens.) de jefatura de hogar según sexo. Tierra del Fuego, AeIAS. 2003-2015.

\begin{tabular}{|c|c|c|c|}
\hline Año & Varón & Mujer & Diferencia \\
\hline 2003 & $\$ 400,00$ & $\$ 300,00$ & $\$ 100,00$ \\
\hline 2004 & $\$ 490,00$ & $\$ 333,33$ & $\$ 156,67$ \\
\hline 2005 & $\$ 716,67$ & $\$ 526,67$ & $\$ 190,00$ \\
\hline 2006 & $\$ 1.000,00$ & $\$ 666,67$ & $\$ 333,33$ \\
\hline 2007 & $\$ 1.200,00$ & $\$ 1.133,33$ & $\$ 66,67$ \\
\hline 2008 & $\$ 1.500,00$ & $\$ 1.325$ & $\$ 175,00$ \\
\hline 2009 & $\$ 1.750,00$ & $\$ 1.500$ & $\$ 250,00$ \\
\hline 2010 & $\$ 2.200,00$ & $\$ 2.000$ & $\$ 200,00$ \\
\hline 2011 & $\$ 2.800,00$ & $\$ 2.700$ & $\$ 100,00$ \\
\hline 2012 & $\$ 3.540,00$ & $\$ 3.666,67$ & $\$-126,67$ \\
\hline 2013 & $\$ 5.000,00$ & $\$ 5.000$ & $\$$ \\
\hline 2014 & $\$ 6.333,33$ & $\$ 6.000$ & $\$ 333,33$ \\
\hline 2015 & $\$ 8.166,67$ & $\$ 7.500$ & $\$ 666,67$ \\
\hline
\end{tabular}

Fuente: Elaboración propia en base a datos de la EPH. Aglomerado 31. Cuestionario individual.2003-2015.

\section{Comentarios finales}

En base a la reconstrucción de los perfiles sociales y ocupacionales de las jefas y los jefes de hogar, se establece una aproximación a la noción de la división sexual del trabajo y a algunas de sus múltiples expresiones concretas, donde se conjugan diferentes formas de desigualdad de género, social y económica; generadas por la segregación que supone dicha división, ya sea dentro del ámbito laboral como en la constitución de los hogares fueguinos.

Asimismo, se ha podido evidenciar que, la doble carga femenina requiere ser estudiada a partir de la perspectiva del uso del tiempo ya que, de esta forma, se establece la relación que condiciona la participación femenina como masculina dentro del el ámbito público; del trabajo y del empleo, como dentro del ámbito privado; de la maternidad/paternidad, la organización y gestión hogareña, así como del cuidado de la familiar y el trabajo doméstico. Esas expresiones diferenciales y desiguales derivan en menores niveles de ingresos femeninos, tanto individuales como per cápita familiares, en hogares con JF, así como en menores posibilidades de empleabilidad, a pesar del considerable incremento en la profesionalización del colectivo de jefas mujeres; de esta manera, se reconocen caracterizaciones precarizantes a la economía femenina.

Por último, en lo que refiere al acercamiento empírico de esta investigación, se pudo concluir que, en cuanto al objeto de estudio, se identificaron ciertas limitaciones dadas por la carencia de información cuantitativa con perspectiva de género con alcances nacionales y/o provinciales. La información extraída de la Encuesta Permanente de Hogares; proporcionados por el INDEC, se constituye en base a la categoría sexo, 
la cual limita y circunscribe a los mismos a patrones normativos binarios y heterosexuales. De esta manera, se puede decir que los datos son insuficientes para caracterizar las múltiples identificaciones genéricas y problemáticas actuales derivadas que impiden visibilizar las múltiples transformaciones y procesos culturales, sociales, políticos y económicos producidos en el país; pero resultan un primer paso para comenzar a pensar en estos temas.

\section{ReFERENCIAS}

Ariño, M. (2007). Familias tradicionales, nuevas familias. En S. Torrado (Ed.), Población y Bienestar en Argentina del Primero al Segundo Centenario. Una historia social del siglo XX, Tomo I, pp. 256-283. Buenos Aires: Edhasa.

Basualdo, E. (2011). Sistema político y modelo de acumulación. Tres ensayos sobre la Argentina actual. Buenos Aires: Atuel.

Burin, M. (2004). Género femenino, familia y carrera laboral: conflictos vigentes. Subjetividad y procesos cognitivos. Buenos Aires: Universidad de Ciencias Empresariales y Sociales (UCES).

Carrasquer, P., Torns, T., Tejero, E., y Romero, A. (1998). El trabajo reproductivo. Papers, (55), 95-114. Recuperado de https://ddd.uab.cat/pub/papers/02102862n55/02102862n55p95.pdf

De la Serna, C. (2010). La transformación del mundo del trabajo: representaciones, prácticas e identidades. Buenos Aires: Fundación Centro de Integración, Comunicación, Cultura y Sociedad - CICCUS; Consejo Latinoamericano de Ciencias Sociales - CLACSO. Recuperado de http://biblioteca.clacso.edu.ar/clacso/becas/2012041805111 2/transformacion.pdf

Neffa, J.C. (1999). Actividad, trabajo y empleo: algunas reflexiones sobre un tema en debate. Orientación y sociedad, 1, 1-35. Recuperado de http://sedici.unlp.edu.ar/bitstream/handle/10915/13870/Documento_completo.pdf? sequence $=1$

Icart, I y Velasco, C. (2016). La economía feminista y la división sexual del trabajo. Culturales, 4 (1), 61-86. Recuperado de http://www.scielo.org.mx/scielo.php?script=sci_arttext\&pid=S1870-11912016000100061

Pateman, C. (1995). Hacer un contrato. En El contrato sexual (pp. 9-30). México: Anthropos: Universidad Autónoma Metropolitana.

Pautassi, L. (2007). El cuidado como cuestión social desde un enfoque de derechos. Santiago de Chile: Naciones Unidas, CEPAL.

Torns, T. (1995). Mercado de trabajo y desigualdades de género. Cuadernos de Relaciones Laborales, (6), 81-92. Recuperado de https://revistas.ucm.es/index.php/CRLA/article/download/CRLA9595120081A/32620

Torrado, S. (1995). Vivir apurado para morirse joven. Reflexiones sobre la transferencia intergeneracional de la pobreza. Revista Sociedad, (7), 31-56.

\section{NoTAS}

1 Se utilizarán las expresiones “o/a"-"o/as"-"a/o"-"a/os" como una forma de no masculinizar el lenguaje implementado. Aunque, igualmente, se recae en la dicotomía masculino/femenino, no hemos optado por la utilización de palabras con sílabas terminadas en "e" o "es" para dar cuenta de una diversidad genérica implícita, ya que actualmente, las producciones académicas con su implementación son poco frecuentes.

2 Según el INDEC, el concepto “jefa o jefe de hogar” refiere a aquella persona reconocida como tal por los demás miembros del hogar. Aun así, se podría ampliar su definición a partir de la auto-asignación, por motivos económicos como principal sostén del hogar o socio-culturalmente atribuida a la autoridad y responsabilidad familiar, para la toma de decisiones.

3 En contraste a la utilización de la noción de "diferencia", "desigualdad" se conceptualiza visibilizando las relaciones de poder existentes en relación al colectivo masculino y femenino respectivamente y a su consecuente discriminación dentro del mercado de trabajo; ámbito público y dentro de la organización familiar; ámbito privado (Torns, 1995).

4 Cuando se hace referencia al concepto de sistema binario y heteronormado se debe mencionar que, si bien no es el eje central del texto, se lo considera como una arista temática estrictamente ligada al eje central. 